\title{
The evaluation of learning in the public universities of Ecuador
}

\begin{abstract}
The present study focused on identifying the methodology of learning is applied in the processes of vocational training in public higher education institutions of Ecuador undergraduate careers and whose range encompassed to sample of the population of teachers of Education Sciences careers. The process of research is descriptive, used quantitative and qualitative approach, the modalities of research were field and bibliographic- documentary, applied survey technique with the questionnaire as an instrument for the collection of evidence from the investigation of research, to then proceed to analyze and Process them using the Excel program allowing you to find valuable results in terms of objects techniques and instruments which apply teachers to assess the learning of the students in the different subjects of the curriculum of studies. The investigative process is concluded that evaluation is a process in which several elements of the learning process are valued in qualitative and quantitative way. The techniques and tools that teachers use to assess are not unified so they are more likely to be teachers as well as the nature and complexity of the subjects and even content to evaluate, this allows you to determine the use of techniques and instruments of evaluation more Compatible with the objects with the nature of the objects of evaluation is necessary.
\end{abstract}

Keywords: evaluation, learning, methodology, professional, training, learning, accreditation, qualification, assessment, training, learning, accreditation, rating methodology

\section{Introduction}

The evaluation of learning is a process and at the same time one of the most relevant components in the context of the professional training of university students, it is oriented to establish results based on indicators of initial knowledge, lessons learned in the process and The aspects taken into account for the assignment of the qualification and the corresponding accreditation that responds to established institutional norms. The methodology of evaluation of learning should be directly related to the guidelines of the respective educational and pedagogical model in force in the respective institution of higher education and that in summary require a systematic, critical, processual, qualitative, quantitative and above all improvement of the Lessons learned and the training process itself. Specifically, the learning assessment methodology is established in the respective syllabus, so teachers base their planning and execution work according to established guidelines and the respective objects of evaluation, however there are lags of a traditional assessment methodology Almost always focusing solely on content and knowledge. In this context, the present study aims to establish in a precise and objective way the methodology, techniques and instruments that are currently applied in the careers of educational sciences that were investigated while establishing the relevance they have in the entire training process Of the students of the mentioned university races, this information will serve as the basis for the future application of methodological proposals oriented to their improvement and permanent innovation.

In the present study the evaluation of learning is a basic element in the formative process, it is complemented by teaching methodology, scientific content, teaching techniques and educational media. In particular, learning evaluation is an integral, complex process, Systematically, this criterion coincides with what it expresses. "The evaluation must comprise each and every one of the elements that intervene in the formation of the human personality, taking into
Volume 2 Issue 6 - 2018

\author{
Luis Alcívar Quizhpe Salinas,' Ángel Serafín \\ Quizhpe Salinas ${ }^{2}$ \\ 'Department of Education Sciences, National University of Loja, \\ Ecuador \\ ${ }^{2}$ Department of Human and Social Sciences, University of the \\ Armed Forces ESPE, Ecuador
}

Correspondence: Luis Alcívar Quizhpe Salinas, Department of Education Sciences, National University of Loja, Ecuador, Email Luisquizhpes@yahoo.es

Received: July 27, 2017 | Published: December 28, 2018 account both the spontaneous or unsystematic form of the home, neighborhood, Friends, cinema, radio, television, social institutions, ... among others.

The evaluation of learning should also have some basic characteristics that would come to scientifically substantiate the process ${ }^{2}$ are cited:

a) Totalizer, integrating the learning process into a conception of educational practice, decomposing its substantive elements to approach its essence.

b) Historical, that recovers the social dimensions of the group happening.

c) Comprehensive, which not only describes the situation of group development, but also provides elements of interpretation of the teaching situation that prevails in the institution.

d) Transformer, which allows not only a correct reading of the prevailing reality, but also facilitates the production of knowledge as well as operate with that reality and modify it.

That is to say, to propose a dialectical revision of theory and practice that derives in a true praxis. The theoretical orientation mentioned above is complemented in terms of ${ }^{3}$ the evaluation is understood as a stage of the educational process that has the purpose of systematically verifying to what extent the expected results have been achieved in the objectives that were specified in advance. An integrated and determinant aspect in the evaluation of learning constitutes the accreditation that comes to constitute in the synthesis of the whole evaluation process, this criterion is part of the tendency of critical didactics in what refers to evaluation, therefore it is necessary to express, ${ }^{4}$ the evaluation responds above all to scientific theoretical approaches and accreditation is primarily a matter of institutional character, since each educational institution has established rules 
regarding the certification of acquired knowledge. Understood thus, accreditation will come first and foremost to constitute a specific and particular instance of the student's professional training process, this is specified in an academic report generated by the teacher towards the educational institution in relation to the student's performance and participation in the whole Process as well as the development of evaluation techniques.

It is also important to note that accreditation cannot be considered only as a technical problem because it is fundamentally social because of the individual and social implications of certification of knowledge. When carrying out the accreditation of learning, qualitative and quantitative information is integrated, the objects of evaluation are evaluated, the equivalents of the qualification are determined and, therefore, the respective qualification is established, therefore, to accredit is to give a formal testimony that the Student has fulfilled the requirements established for the effect, these requirements have to do with the management of certain important contents raised in the plans and programs of study and with the respective results. The evaluation and accreditation process are therefore complementary processes. ${ }^{5}$ The evaluation - accreditation process results in a value judgment from a deep knowledge to issue a substantiated judgment that is concretized in the approval or not of the student.

\section{Methodology}

Once the research problem was formulated, we proceeded to select the research methodology that corresponded to the object of study, so the type of research selected was the descriptive one supported by qualitative and quantitative procedures and documentary study. The technique applied is the survey using as a research instrument the questionnaire the same one that prior to its application was submitted to a pilot validation test. The instrument cited was applied to a total of eighty-seven teachers from ten public universities in Ecuador offering undergraduate degrees in education sciences. The treatment of the empirical data obtained was tabulated and scrutinized using the Excel computer program, which is presented in the respective graphs.

\section{Evaluation of results and discussion}

The results presented below correspond to surveys applied to teachers of the courses of face-to-face education of the public universities of the country; the same is presented in the graphs with their respective analysis. The survey was designed taking into account the objects of evaluation, Hernández ${ }^{6}$ techniques, instruments applied by teachers of the various subjects of the races investigated. The results are presented below: When teachers consulted about their concept of diagnostic evaluation of learning, most agree that this is done at the beginning of the training process and can be done through a conversation or an examination. A smaller percentage considers that this is oriented to establish the initial situation of learning. The relation to the processual evaluation of learning, a significant percentage of those surveyed consider that this type of evaluation is developed during the semester and also consider that it also involves the learning process, is also oriented to learning recovery strategies, Reinforce the contents.

a) Define Summative Evaluation? The summative evaluation is done through the content test and the examination that allows the assignment of the respective qualification to the students, also this is done as a context assessment. b) What do you think about the final evaluation via exam? The final or summative evaluation that is done through the exam is important for the majority of respondents since it allows to summarize the knowledge acquired by the students during the academic period.

c) What is the difference between evaluation and accreditation? The most important difference that respondents find regarding the evaluation and accreditation of learning is that the evaluation is done on a permanent basis and accreditation is done at the end and aims at the respective qualification.

d) Do you propose four aspects that allow you to evaluate the learning achieved by the students? The practice of what is learned and the lessons are the main aspects that allow to evaluate the learnings of the students according to criterion of the respondents to that is added the examination of knowledge.

e) How often do you rate students' learning? Teachers evaluate students every day according to the researchers, another important group of teachers evaluate in periods of one week.

f) Who participates in the evaluation process? In the process of evaluating learning, teachers and students participate; a minority of respondents expressed that only the students participate.

g) Does the test that is applied at the end of the didactic unit determine the student's accreditation? The test of knowledge is not decisive in the accreditation according to the majority of respondents, this explains that effectively the evaluation that is applied is procedural.

h) How do you determine the level of mastery of the content? The mastery of contents and the own learning achieved by the students is determined through the accomplishment of practical exercises and the development of skills and skills related to the formative process.

i) What is the procedure for identifying the application capacity? The ability to apply the knowledge gained in the training process is established through the execution of research and projects linked to the subjects. Written lessons are also a valid mechanism for this purpose.

j) How do you rate students' attitudes? Students' attitudes are evaluated in an evaluation process, and these according to the majority of respondents are positive and optimistic followed by the criterion that they are very important.

k) In the context of the Assessment and Accreditation of learning and considering its level of importance, assign a qualification to the knowledge domain? The domain content studied in the training process are very important for the majority of respondents, a lower percentage considered to be moderately important, this criterion implicitly reflects the presence of traditional evaluation traits.

1) In the context of the Assessment and Accreditation of learning and considering its level of importance, assign a score to Procedural Aspects? The procedural aspects and the evaluation itself as a process are very important for the majority of teachers investigated.

m) In the context of the Evaluation and Accreditation of learning and considering its level of importance, assign a rating to Actitudinal 
Aspects? Attitudinal and behavioral aspects of the students in the training process are very important when applying the evaluation of learning.

n) Does it apply feedback in the evaluation process? Most of the researched teachers consider that they do apply the feedback as a strategy that allows improving the learning achieved by the students.

o) What strategies do you use to improve evaluation results? Teachers apply different strategies to improve the results of the evaluation of learning achieved by students; among others are the completion of work, feedback, tutoring, individual and group work and motivation.

p) What aspects determine the qualification of the students? Students' qualifications are determined by class participation, homework, work and research, the final exam, and the lessons given by students in the development of the training process.

q) What types of questions do you use in the assessment tests? The majority of teachers investigated consider that the types of questions that integrate in the evaluation tests are those of reasoning and reflection, are also the multiple selection, open and closed, examples and the test, this allows to establish that the tests correspond to A processual evaluation.

r) What kinds of techniques do you use most often to evaluate student learning? The assessment techniques applied by teachers are cited in order of importance the debate, exhibitions, demonstration classes, participation, reports and reports and workshops.

s) What kinds of instruments do you use most frequently to assess student learning? The instruments used to evaluate student learning are tests, lessons, work, workshops, these reflect the application of a processual evaluation.

\section{Conclusions and future work}

The survey instruments applied to the investigated teachers allowed to establish the aspects that are considered as objects of evaluation, the methodology of evaluation of learnings as well as the techniques, instruments and the procedure that apply to establish the qualification in the respective subjects. Institutions of higher education through the educational model and specifically the syllabus facilitate methodological guidelines to apply the evaluation, accreditation and qualification of student learning, The evaluation of the learning involves the assessment made by teachers regarding the knowledge achieved by students to which is added the procedures and attitudes, this allows to affirm that the methodology of evaluation of learning that predominates in the institutions investigated by processes, Systematic and integral, it is possible to indicate that there are certain lags of evaluation of learning that apply the teachers of the races investigated which must be overcome. In the higher education institutions investigated, a systematic and comprehensive evaluation is applied, so that the final qualification is the sum of partial qualifications awarded to several objects of evaluation, in addition the knowledge test is oriented to the analysis, reflection, construction, resolution from problems.

Based on the aforementioned, it is possible to be affirmed that a methodological process of investigation was effectively applied that allowed to establish the methodology of evaluation of learning that is applied in the careers of sciences of the education of the public universities of the country which were object of study And that therefore this information will allow other researchers to take the basis for their research in the context of Ecuadorian higher education.

\section{Acknowledgments}

None.

\section{Conflicts of interest}

The author declares that there are no conflicts of interest.

\section{References}

1. Victor S. Elements of Measurement and Evaluation in the educational field. Quito: University; 2001.

2. Porfirio MO. Proposal of Evaluation and Accreditation in the process of teaching learning from a group perspective. Mexico Federal District: UNAM; 1980.

3. Lafourcade P. Evaluation of learning. Buenos Aires: Kapelusz; 2000. $16 \mathrm{p}$.

4. Barriga AD. Evaluation Proposal-Accreditation in the teaching-learning process from a group perspective. Mexico City: UNAM; 2000. 33 p.

5. Barriga AD. Thesis for a theory of evaluation and its derivations in teaching. Mexico City: UNAM; 1990. 298 p.

6. Hernández J, Martínez P. Guidelines for evaluation of an orientation program. Journal of Educational Research.1994;1(2):1-16. 